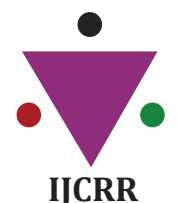

Section: Healthcare

ISI Impact Factor

(2019-20): 1.628

IC Value (2019): 90.81

$\operatorname{SJIF}(2020)=7.893$

(c) (i) (3)

Copyright@IJCRR

\title{
"Comparative Evaluation of Antifungal Effect of Origanum Oil Solution and Povidone Iodine Aqueous Solution on Scleral Resin: An In-Vitro Study"
}

\author{
Pande Samidha S. ${ }^{1}$, Sathe Kambala Seema ${ }^{2}$, Godbole Dubey Surekha ${ }^{3}$, \\ Revankar Ramnath P. ${ }^{4}$
}

\begin{abstract}
1111 MDS, Department of Prosthodontics and Crown \& Bridge, Sharad Pawar Dental College, Wardha, Maharashtra, India; ${ }^{2}$ Professor and Head, Department of Prosthodontics and Crown \& Bridge, Sharad Pawar Dental College, Wardha, Maharashtra, India; 3Professor, Department of Prosthodontics and Crown \& Bridge, Sharad Pawar Dental College, Wardha, Maharashtra, India; ${ }^{4}$ Assistant Professor, Department of Prosthodontics and Crown \& Bridge, Sharad Pawar Dental College, Wardha, Maharashtra, India.
\end{abstract}

\section{ABSTRACT}

Aim: To compare and evaluate the antifungal effect of origanum oil and povidone-iodine aqueous solution on scleral resin.

Introduction: Ocular prosthesis being a part of maxillofacial prosthodontics aims to restore and repair the ophthalmic cavity. An important prerequisite for a prosthesis is the eradication of plaque accumulation due to bacteria. To neglect probable infections in the patient's ophthalmic cavity a naturally available antifungal agent was tested in this study.

Methods and Material: In this study, 40 custom made scleral resin disks (20 in each group) immersed in 2 different solutions were studied for their antifungal activity. The evaluation of this property was done by calculating the zone of inhibition around the disks propelled in the specific agar media.

Statistical Analysis: Descriptive and analytical statistics were done. The data is represented in mean and standard deviation. The normality of continuous data was analysed by the Shapiro-Wilk test. As the data followed a normal distribution, parametric tests were used to analyse the data. The independent sample t-test and paired sample t-test were used to check to mean differences. The level of significance was kept at $p<0.05$. The software used wasSPSS (StatisticalPackagefor Social Sciences) Version 24.0 (IBM Corporation, Chicago, USA)

Results: The antifungal efficacy of the origanum oil solution was found to be significantly higher than the povidone-iodine solution.

Conclusion: This study concluded that origanumoil is a potent antifungal against C. Albicans. This encourages the researcher to assess the effectiveness of $O$. vulgare oil in other forms of systemic and superficial fungal infections as well as to investigate its broad-spectrum outcome against other pathogenic manifestations which also include malignancies.

Key Words: Ocular prosthesis, Antifungal, Origanum oil, C.Albicans, SDA, Maxillofacial, Prosthetics

\section{INTRODUCTION}

Ocular prosthesis is a part of maxillofacial prosthodontics that aims to restore and repair the ophthalmic cavity which aims in beautifying the compromised patients face. It also aids to improve the psychology and social development of the patient thus enhancing the quality of life. ${ }^{1}$

The ocular prosthesis has seen exponential growth for a decade. This development is due to improved materials, enhanced postoperative management and the rising patient requirement. A diversity of materials are being used nowadays for ocular prostheses. ${ }^{2}$
As this prosthesis has an intimate and dynamic relationship with the ocular surface it carries a threat of infection throughout their life and has a major effect on the esthetics of the patient esthetics. Proper function and retention act as an important factors in the success of this type of prosthesis. ${ }^{2}$

An important prerequisite for a prosthesis is the eradication of plaque accumulation due to bacteria. To neglect probable infections in the patient's ophthalmic cavity, the ocular prosthesis should be removed on a routine basis and disinfection should be done; after which it can be inserted again. ${ }^{3}$

\section{Corresponding Author:}

Dr. Samidha Shailendra Pande, 202 Department of prosthodontics, Sharad Pawar Dental College, Wardha, Maharashtra, India. Email: samidhashailesh@gmail.com

ISSN: 2231-2196 (Print)

Received: 08.02 .2021
ISSN: 0975-5241 (Online)

Revised: 12.03 .2021
Accepted: 05.04.2021
Published: 24.10 .2021 


\section{AIM}

To compare and evaluate the antifungal effect of origanum oil and povidone-iodine aqueous solution on scleral resin

\section{OBJECTIVES}

- Evaluation of the antifungal effect of origanum oil solution on scleral resin

- Evaluation of the antifungal effect of povidone-iodine aqueous solution on scleral resin

- To compare and determine the efficacy of antifungal property of origanum oil solution with the povidoneiodine aqueous solution on scleral resin

\section{STUDY DESIGN AND METHODOLOGY}

\section{MATERIALS USED}

1. Scleral resin disks

2. Povidone-iodine aqueous solution

3. Origanum oil solution

\section{PREPARATION OF SAMPLE AND GROUPS-}

- Preparation of scleral resin disks (40) using a custom mould was done and was divided into two groups ( Group A (20)-scleral resin to be immersed in origanum oil solution Group B(20)-scleral resin to be immersed in povidone-iodine aqueous solution) [Fig.1]

\section{METHOD TO CHECK ANTIFUNGAL PROPERTY}

- The fungal suspension containing strains of C. Albicans was prepared.[Fig.2] Scleral resin disks of both the groups (A and $\mathrm{B}$ ) were immersed in the fungal suspension for the desired period after which the disks were incubated for $24 \mathrm{hrs}$ for the organisms to grow

\section{Phase I}

- A sterile swab was taken from the surface of these incubated disks and cultured in Sabouraud's dextrose agar (SDA) and incubated at $37^{\circ} \mathrm{C}$. The disks of group A were immersed in an origanum oil solution $(60 \%)$ and the disks of group B in $10 \%$ povidone-iodine aqueous solution(betadine) [Fig.3]

\section{Phase II}

- After 15 minutes of immersion of the disks of both groups in the two solutions, the antifungal potential of the testing solutions was evaluated by Agar well diffusion method. For this evaluation, previously cultured Petri dishes containing Sabouraud's dextrose agar (SDA) which were cultured using the swab technique for C. Albicans were taken. After this, the plates containing agar were left for drying. Using sterile cork borer 3 wells or cups were made. The disks which were immersed in the solution were inserted in the wells of the inoculation of the particular media agar plates. [Fig.4] The plates were kept on hold for $10 \mathrm{~min}$ so that essential oils get diffused. After which incubation of these plates was carried out at $37^{\circ} \mathrm{C}$ for 48 h. Finally, after the incubation period, examination of plates detected the existence of clear zones of growth inhibition surrounded the wells which contained the testing solutions, which pointed to their efficacy against C.albicans. [Fig.5] The zone of inhibition was recognized by measurement of the good diameter (in millimetres) in one plane using the Vernier scale.[Table 1].

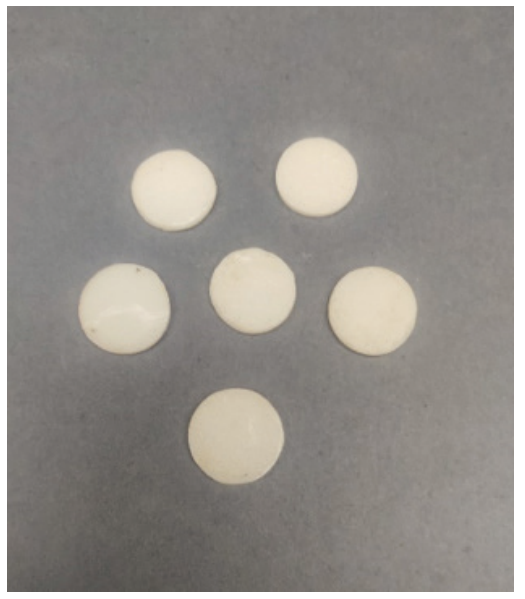

Figure 1: Custom Made Scleral Resin Disks.

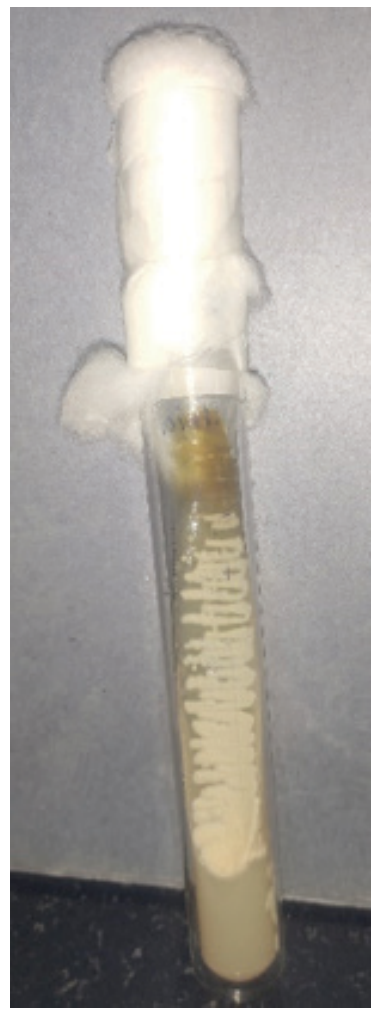

Figure 2: Candidal Growth Used for Broth Preparation. 


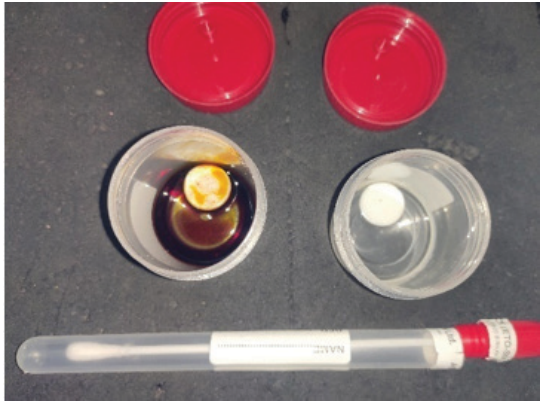

Figure 3: Scleral Resin Disk Immersed in Povidone lodinesolution and Origanum Oil Solution.

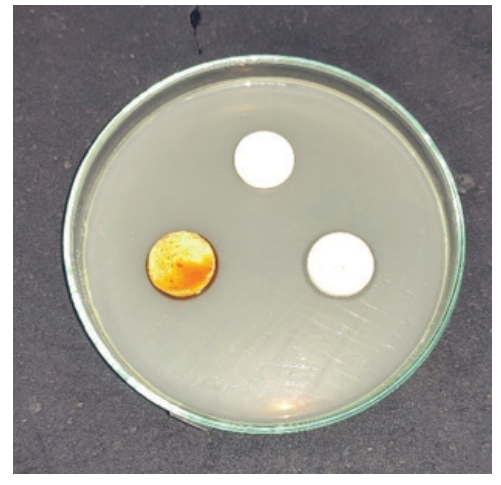

Figure 4: Scleral Resin Disks Immersed in Two Solutions Along with a Control Group Disk Propelled in Sda Platesinnoculated With Candida.

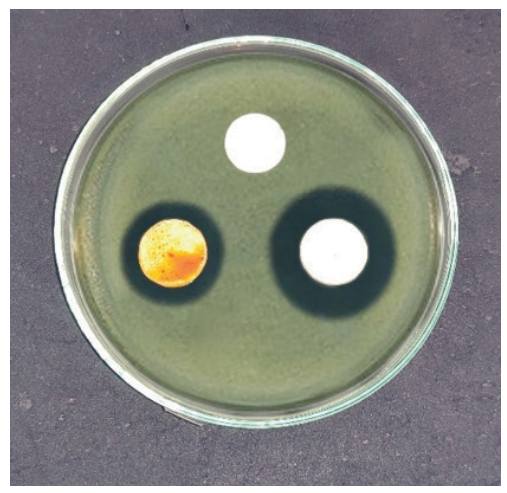

Figure 5: Scleral Resin Disks Immersed in Two Solutions Along with a Control Group Disk Propelled in SDA Platesinnoculated with Candida Showing Zone of Inhibition.
Table 1: Diameter of the inhibition zone calculated by vernier calliper in millimetres $(\mathrm{mm})$.

\begin{tabular}{lcc} 
Sample no. & $\begin{array}{c}\text { Povidone lodine aque- } \\
\text { ous solution }(\mathrm{mm})\end{array}$ & $\begin{array}{c}\text { Origanum oil } \\
(\mathrm{mm})\end{array}$ \\
\hline 1 & 17 & $>40$ \\
2 & 16 & $>40$ \\
3 & 11 & $>40$ \\
4 & 12 & 32 \\
5 & 17 & 34 \\
6 & 16 & $>40$ \\
7 & 18 & $>40$ \\
8 & 7 & 22 \\
9 & 10 & $>40$ \\
10 & 12 & 18 \\
11 & 11 & $>40$ \\
12 & 17 & $>40$ \\
13 & 16 & 36 \\
14 & 12 & 38 \\
15 & 17 & $>40$ \\
\hline
\end{tabular}

\section{STATISTICAL ANALYSIS}

Descriptive and analytical statistics were done. The data is represented in mean and standard deviation. The normality of continuous data was analysed by the Shapiro-Wilk test. As the data followed a normal distribution, parametric tests were used to analyse the data. The independent sample t-test and paired sample t-test were used to check to mean differences. The level of significance was kept at $\mathrm{P}<0.05$.

Software: SPSS (StatisticalPackagefor Social Sciences) Version 24.0 (IBM Corporation, Chicago, USA)

\section{OBSERVATION AND RESULTS}

\section{Output Tables:}

Table 2: Comparison of the mean zone of inhibition of candida Albicans by origanum oil solution and povidone-iodine aqueous solution on scleral resin

\begin{tabular}{lcccccccc} 
Groups & N & Mean & S.D. & S.E. & M.D. & $95 \%$ C.I. & t-value & P-value \\
Povidone Iodine & 15 & 13.93 & 3.36 & 0.86 & -23.33 & $-27.65^{--19.00}$ & -11.053 & $<0.001^{\dagger}$ \\
Origanum oil & 15 & 37.26 & 7.44 & 1.92 & & & \\
\hline
\end{tabular}

\#P-value derived from independent sample t-test; ${ }^{\dagger}$ significant at $\mathrm{P}<0.05$ 
The mean zone of inhibition of candida Albicans by origanum oil solution and povidone-iodine aqueous solution on the scleral resin was compared. It was found that there was a highly statistically significant difference in the mean zone of inhibition of candida albicans $(\mathrm{P}<0.001)$. The mean zone of inhibition of povidone iodine aqueous solution $(13.93 \pm 3.36)$ was significantly lesser than that of origanum oil solution (37.26 \pm 7.44). [Table.2]

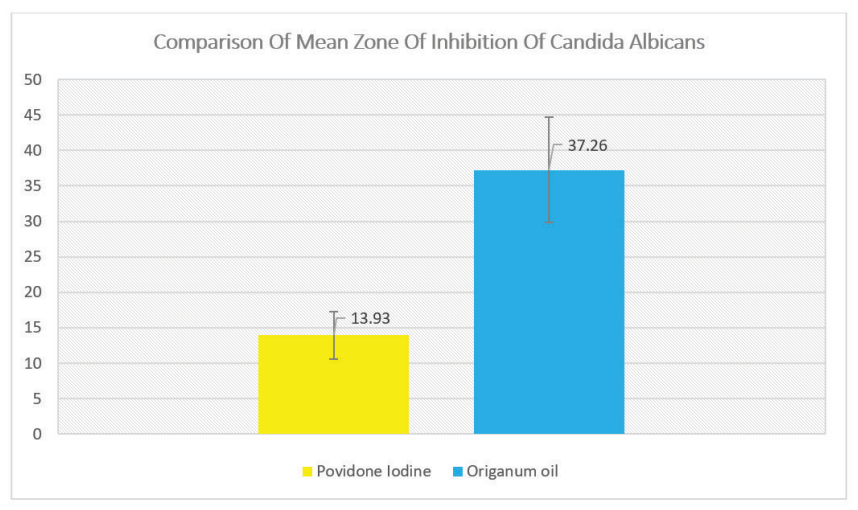

Graph 1: Comparison of the mean zone of inhibition of candida Albicans by origanum oil solution and povidone-iodine aqueous solution on scleral resin.

\section{DISCUSSION}

Nowadays, drug resistance for multiple drugs in the human pathogenic microbes are observed at a high rate this is a result of excessive use or abuse of commercially available antimicrobial drugs. Resistant strains of Candida albicans are becoming a reason for major health concerns, and thus new antifungal agents are required to overcome this issue. This situation has encouraged the researchers to develop some new and effective antimicrobial agents that have the potential to replace the regimens currently used.

For a long time, medicinal plants are playing a vital role in promoting healthy mankind. Traditional medicines have always been economical and readily available sources of management in the principal health care system of indigent communities and countries. More than $80 \%$ of the people in the developing countries make use of traditional medicines reason being the non-affordability of the marketed medicines available for health care and also because these unconventional medicines are more suitable from a cultural and spiritual perspective. ${ }^{8}$

In the presenting study, the in vitro antifungal actions of Origanum essential oil, as well as povidone iodine aqueous solution in opposition to C. albicans, were compared. Thus resulting in a significant impact on the growing trend in the usage of herbal products in medicine.
C. Albicans is a dimorphic, yeast-like fungus residing as a commensal in the mucocutaneous areas in the body like the skin, the vagina and the intestine of humans. It can lead to infections under altered physiological and pathological circumstances such as "infancy, pregnancy, diabetes, prolonged broad spectrum antibiotic administration, steroidal chemotherapy and acquired immune deficiency syndrome". ${ }^{9}$

The Origanum oil commonly known as Ajwain is a perennial creeper cultivated in most parts of India. The essential oil extracted from $\mathrm{O}$. Vulgare has an inhibitory outcome on fungal species of clinical importance. ${ }^{10,11}$ Therefore, this study aimed to compare the antifungal activities of $\mathrm{O}$. Vulgare essential oil and povidone-iodine aqueous solution on C. Albicans.

To check the efficacy as well as analysing the antimicrobial action of origanum oil against povidone-iodine solution an accepted and effective method of Agar well diffusion was used. ${ }^{12}$ The clear zone [area of inhibition] by the above technique for origanum oil was found to be $>40 \mathrm{~mm}$ which was comparatively higher than the povidone iodine aqueous solution. Thus a conclusion was driven that C. Albicans was most sensitive for O. Vulgare oil when compared to the povidoneiodine aqueous solution.

Manohar et al. ${ }^{6}$ in which C. Albicans was found to be sensitive to $\mathrm{O}$. Vulgare at a concentration of $0.2 \%$ using broth micro-dilution method. Another study reported by Adams et al. ${ }^{13}$ found that higher antifungal properties are seen in Origanum oil due to its main content being carvacrol.$^{6,14}$ and are responsible for the antifungal and antibacterial activities. They cause alterations in the cell membrane configuration ensuing in the interruption of the permeability barrier of microbial membrane formation. ${ }^{6}$

In the patients with an ocular prosthesis, advice to clean the prosthesis with soap solution is given to maintain its hygiene. ${ }^{15}$ In this study, an antifungal solution of O.vulgare oil which can aid in maintaining the hygiene of the prosthesis was found to be a more effective antifungal agent against C. Albicans when compared to the povidone-iodine aqueous solution. This study helps in promoting traditional medicine form of modern dentistry, as $O$. Vulgare essential oil is easily accessible, economically feasible, culturally acceptable and less toxic.

\section{CONCLUSION}

This study encourages the researcher to assess the effectiveness of $O$. Vulgare oil in other forms of systemic and superficial fungal infections as well as to investigate its broadspectrum outcome against other pathogenic manifestations which also include malignancies. Further research may be performed to examine the detailed mechanism of the action 
of Origanum oil in various metabolic behaviour in humans, which will, in turn, be helpful to mankind.

\section{ACKNOWLEDGEMENT}

Authors acknowledge the immense help received from the scholars whose articles are cited and included in references of this manuscript. The authors are also grateful to authors/ editors/publishers of all those articles, journals and books from where the literature for this article has been reviewed and discussed.

\section{Source of Funding: None}

\section{Conflict of Interest: None}

Authors' Contribution: All the authors have contributed to the planning, implementation and analysis of the research study and its presentation in the form of the manuscript.

\section{REFERENCES}

1. Garg A, Shenoy KK. A comparative evaluation of the effect on water sorption and solubility of a temporary soft denture liner material when stored either in distilled water, 5.25\% sodium hypochlorite or artificial saliva: An in vitro study. J Indian Prosthodont Soc. 2016 Jan;16(1):53.

2. Kawano F, Dootz ER, Koran Iii A, Craig RG. Sorption and solubility of 12 soft denture liners. J Prosthet Dent. 1994 Oct 1;72(4):393-8.

3. Council on Dental Materials. Revised ADA specification no 12 for denture base polymer. J Am Dent Assoc. 1975;90:145-54

4. Srivatstava A, Ginjupalli K, Perampalli NU, Bhat N, Ballal M. Evaluation of the properties of a tissue conditioner containing origanum oil as an antifungal additive. J Prosthet Dent. 2013 Oct $1 ; 110(4): 313-9$.
5. Aziz HK. Evaluation of adding ginger oil on sorption and solubility of soft liners using different saliva $\mathrm{pH}$ levels. Iraqi Dent.J. 2015 Aug 15;37(2):43-50.

6. Manohar V, Ingram C, Gray J, Talpur NA, Echard BW, Bagchi Det al.Antifungal activities of origanum oil against Candida albicans. Mol Cell Biochem. 2001 Dec 1;228(1-2):111-7.

7. Kanathila H, Bhat AM, Krishna PD. The effectiveness of magnesium oxide combined with tissue conditioners in inhibiting the growth of Candida albicans: an in vitro study. Indian J Dent Res. 2011 Jul 1;22(4):613.

8. Hosseinzadeh S, Jafarikukhdan A, Hosseini A, Armand R. The application of medicinal plants in traditional and modern medicine: a review of Thymus vulgaris. Int $\mathrm{J}$ ClinMed. 2015;6(09):635.

9. Williams D, Lewis M. Pathogenesis and treatment of oral candidosis. J. Oral Microbiol. 2011 Jan 1;3(1):5771.

10. Patra B, Das MT, Dey SK. A review on Piper betle L. J Med Plants Stud. 2016;4:185-92.

11. Cleff MB, Meinerz AR, Xavier M, Schuch LF, Meireles MC, Rodrigues MR, Mello JR et al. In vitro activity of Origanum vulgare essential oil against Candida species. Braz J Microbiol. 2010 Mar;41(1):116-23.

12. Reller LB, Weinstein M, Jorgensen JH, Ferraro MJ. Antimicrobial susceptibility testing: a review of general principles and contemporary practices. Clin Infect Dis. 2009 Dec 1;49(11):174955 .

13. Adams A, Kumar S, Clauson M, Sahi S. Anti-yeast activities of Origanum oil against human pathogenic yeasts. Adv Biosci Biotech. 2011 Apr 1;2(2):103.

14. Ali I, Khan FG, Suri KA, Gupta BD, Satti NK, Dutt P, Afrin F, Qazi GN, Khan IA et al. In vitro antifungal activity of hydroxychavicol isolated from Piper bettle L. Ann Clin Microbiol Antimicrob. 2010 Dec 1;9(1):7.

15. Kambala SS, Rathi D, Borle A, Rajanikanth K, Jaiswal T, Dhamande M. et al.Evaluating the colour stability of ocular prosthesis after immersion in three different immersion media: An in vitro study. J IntSoc of Prevent Comm Dent. 2020 Mar 1;10(2):226. 